\section{A man driven by proticity}

T $\mathrm{T}$ came as no surprise, and a great

delight, to hear of Peter Mitchell's Nobel Prize, in Chemistry, for his work on the energetics of biological systems. "Chemiosmotic theory" said the television-news lady unflinchingly, while her raised eyebrows asked what on earth chemiosmosis might be. A good question, and several million viewers momentarily joined the slimmer ranks of those who, in response to Mitchell's paper in Nature on July 8, 1961, had asked much the same. But before the theory, the problem: how do cells derive useful chemical energy (ATP, adenosine triphosphate formed from adenosine diphosphate and phosphate) by oxidising foodstuffs (oxidative phosphorylation) or by absorbing light (photosynthetic phosphorylation)? Or more specifically, how is ATP synthesis coulped to or driven by the electron transfer reactions of oxidative and photosynthetic multienzyme chains?

Earlier theories (Slater, E. C. Nature, $172,975 ; 1953)$ were based on analogies with fermentative modes of ATP synthesis, as occurs in yeasts or muscle anaerobically by a well characterised set of enzyme catalysed reactions and chemical intermediates. All of the necessary enzymes and metabolic intermediates for this sort of ATP synthesis can be reconstituted into an ATP synthesising system in aqueous solution in a test-tube.

These earlier theories, timely as they were, did not provide for the role of membranes (which are the site of the enzymes of oxidative and photosynthetic phosphorylation), and did not provide a necessary link between solute transport across these membranes and some intermediate part of the coupling mechanism. Nor have the predicted chemical intermediates common to both the oxidoreduction reaction and the ATP synthesis (thereby coupling them) been found, despite intensive search.

Theories for a coupling mechanism using energised protons as the coupling intermediate were published by Mitchell (Mitchell, P. Nature, 191, $144 ; 1961$ ) and also by R. J. P. Williams (Williams, R. J. P. J. Theoret. Biol. 1, 1; 1961). Mitchell's theory, which he called chemiosmotic, consists of four basic postulates concerning the appropriate membranes of bacteria, mitochondria and chloroplasts. The postulates (Mitchell, P. "Chemiosmotic Coupling in Oxidative and Photosynthetic Phosphorylation". Glynn Research Ltd., Bodmin, Cornwall; 1966) state that

- photosynthetic and respiratory oxidoreductions are reversibly protontranslocating

so is the membrane-bound ATPase

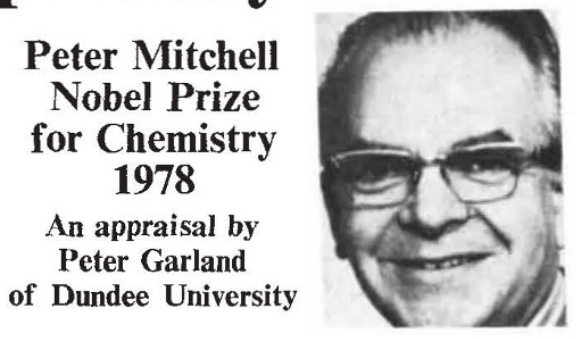

but in the opposite sense across the membrane

- the membrane is impermeable to $\mathrm{H}^{+}, \mathrm{OH}^{-}$and cations and anions generally

- nevertheless, the membrane contains specific carrier systems permitting the entry and exit of metabolites in and out of the bacterium, mitochondrion or chloroplast in response to the electrochemical $\mathrm{H}^{+}$difference set up across the membrane by the first two mechanisms.

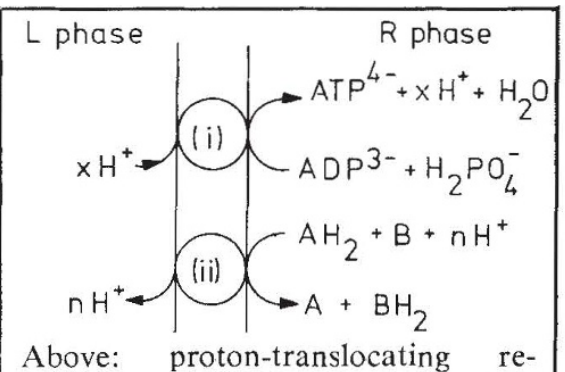

Above: proton-translocating reshowing a proton-impermeable membrane $\mathbf{M}$ that separates aqueous phases $L$ and $R$ from each other. In the membrane are enzyme systems, (i) a proton-translocating ATPase drawn in the thermodynamically unfavourable direction of ATP synthesis, (ii) a proton-translocating oxidoreduction enzyme that oxidises oxidant B, going in the thermodynamically favourable direction. It is postulated that the oxidoreduction, by translocating protons, sets up a difference of electrochemical proton activity-or proton motive force-across the membrane. This proton motive force then drives $\mathrm{H}^{+}$ from left (L) to right (R) through the ATPase, thereby driving ATP synthesis. Thus the oxidoreduction reaction is coupled to the ATPase reaction by a flow of protons. Similar principles apply for photosynthetic oxidoreductions. A scheme in which protons move from the oxidoreduction enzyme to the ATPase via surface layers of the membrane would not in principle be greatly different, in so far as the high and low energy protons, equivalent to protons on the $\mathrm{L}$ and $\mathrm{R}$ faces of the membrane, are kept apart by the proton-impermeability of the membrane in what is still essentially a three phase system.
Overall, these postulates linked electron transport, ATP synthesis and hydrolysis, and solute transport, into a single membrane dependent scheme. Conceptually they linked bioenergetics with classical electrophysiology. Because the theory specified aqueous phases bordering the membrane as the phases in which translocated protons appeared, like other transported ions and solutes, it opened the way to experimental test. Herein lay the unique fertility of the theory. It led to a wide new range of experimental approaches directed to the basic postulates themselves and to topics that would have seemed once to be utterly disparate: bacterial chemotaxis, the regulation of intracellular $\mathrm{Ca}^{2+}$, light harvesting by halophilic purple bacteria, biological hydrogen production, to name but a few.

The experimental demonstration of the basic postulates is widely accepted. Less agreed by far are the molecular mechanisms of proton translocation by the ATPase and oxidoreduction enzymes. Nor have localised proton circuits been excluded. Clearly there is much still to be done, and Mitchell's award will most likely mark an acceleration, not a slowing, of research in bioenergetics-a field which must now be all the more respectable. We can also anticipate vigorous attack not only on the underlying molecular mechanisms but also on the theory itself: can it be unequivocally disproven in its present form, need it be modified, is it sufficient? Whatever the outcome, two things at least are sure to remain. Firstly the immense effect of Mitchell's theory in steering bioenergetics away from chemical intermediates into membrane biology. Secondly, the sheer elegance of the experimental tests published in a series of classical papers by Mitchell and his co-worker, Dr Jennifer Moyle.

Historically, Mitchell's interest in the field of biological membranes can be readily traced from at least his postgraduate student days, when his supervisor at Cambridge was J. F. Danielli (it was Danielli who, with H. Davson, had proposed the phospholipid bilayer structure for biological membranes some twenty years before the advent of electron microscopy allowed such structures to be visualised). By 1952 Mitchell was lecturing on membranes and transport to undergraduates at Cambridge; the lectures were memorable for their style, and if we students were confused by them, reassurance came with the thought that the unconfused did not understand the problem. In 1957 Mitchell (Mitchell, P. Biochem. Soc. Symp. 16, 73; 1959) developed his views further in a lecture 
to the Biochemical Society, and the idea expressed then that enzymes in membranes could act as (reversible) chemical links between the media on either side of the membrane clearly presaged the full publication of his chemiosmotic theory in 1961, when he was at Edinburgh University.

The following years could not have been easy for him. Leaving Edinburgh in 1963 for health reasons, he set up a private laboratory in Bodmin, Corn- wall. As a private foundation it was not eligible for support from government research councils. His theory came under severe attack, much of it based on the failure of critics to understand the postulates. In retrospect it might seem that the work of formulating his theory was trivial compared to that involved, under difficult conditions, in testing and explaining the theory to its present stage of recognition.

The word chemiosmosis has been much argued over, and diversely interpreted. Some say that "osmosis" is wrong. As usual, Popper already has it sewn up, and advises-“"Never let yourself be goaded into taking seriously problems about words and their meanings. What must be taken seriously are questions of fact, and assertions about facts: theories and hypotheses; the problems they solve; and the problems they raise".

\section{news in brief}

- Foreign experts to assess Germany's nuclear plan: To delay a political storm over the West German federal government's decision to build a nuclear reprocessing plant and storage installation, Premier Ernst Albrecht of the state government of Lower Saxony, where the nuclear facility is to be built, has set up a panel of international critics of nuclear energy to review the plans. This is the first time a European government has invited foreign experts to assess civil nuclear policy. Walter Patterson of the Friends of the Earth, and a member of the panel, told Nature that the panel is not just concerned with "the technical nuts and bolts of the project, but is to look into its social and political implications to provide a panoramic overview".

Lower Saxony contains most of West Germany's salt domes, which the nuclear industry and government consider to be the most suitable sites in the country for final storage of high-level radioactive waste. The federal government in Bonn asked Ernst Albrecht to choose one of three recommended domes where the facility should be built. He rejected those three and chose one at Gorleben, which is very close to the border with East Germany. With pressure on one side from Bonn, and on the other from local people and environmental groups hostile to the plan, Albrecht set up the Gorleben International Review in June this year.

The review panel includes ten experts from the US, four from the UK, four from Sweden and two from France. Among them are Professor Karl Morgan, one of the founders of health physics, Paul Sieghart, chairman of the International Commission of Jurists, Dr Frank Barnaby, director of the Stockholm International Peace Research Institute, and Dr Gene Rochlin, who is a member of the Interagency Review Group on nuclear waste management. The panel will submit an interim report probably in February 1979, after which a wide-ranging public hearing will be held. The final report is expected to be submitted by April 1979.

- Ultraviolet radiation risk ignored: Research workers and students in British universities may be risking severe damage to their eyes and skin because safety measures for the use of ultraviolet light in laboratories are being ignored, according to a report by the National Radiological Protection Board (NRPB).

The report states that university staff showed "a general lack of awareness" of the hazards from ultraviolet radiation and of health protection measures. "In general, the standard of engineering controls was inadequate, administrative controls were poor, and although personal protection was available in some cases, there was no warning sign instructing staff to wear it."

Over-exposure to ultraviolet radiation can cause severe skin rashes and can damage the eyes. The main effect on the eyes is photokeratitis, or "arc-eye", which, although not permanent, is extremely painful.
The board investigated 55 installations of ultraviolet equipment in three British universities at the request of their radiation protection officers. Of 24 potentially high risk installations only two had appropriate warning signs, and in only three cases did the staff wear adequate protective equipment such as goggles or gloves.

Very few cases of actual injury have been reported, but as the use of ultraviolet radiation in laboratories increases, says the report, accidents will become more common unless safety measures are taken. Although only three universities were visited, the NRPB regards the attitude to safety it found as probably typical of most research departments.

- More funds for reactor safety research: The West German federal government has decided to increase its expenditure on research into the safety of light water nuclear reactors. This has now become the most rapidly expanding area of nuclear energy research in Germany. DM575 millions (about $£ 160$ millions) of government funds will be spent over the four years 1977 to 1980 on expanding and improving the existing reactor safety research programme. This follows the DM318 millions (about $£ 90$ millions) spent between 1972 and 1976 on over 600 projects.

The new research programme will concentrate on ways of improving the reliability of reactors, and on what would happen in the event of a breakdown, including an analysis of emergency cooling and melt-down of the core, and the exposure of workers to radiation.

- New Fermilab director: Professor Leon Lederman (right) is to be the next director of Fermilab, the US National Accelerator Laboratory at Batavia, Illinois, which contains the world's highest energy $(500 \mathrm{GeV})$ particle accelerator. However, he will not take acting director, until 1 June 1979 over from Dr Philip Livdahl, the because of his commitments at

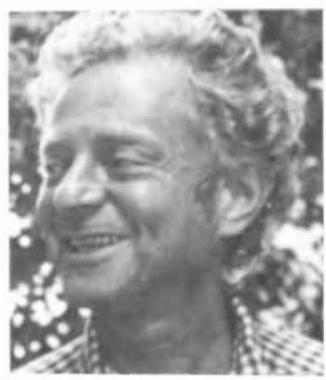
Columbia University where he has been for more than 25 years. He is also the director of Nevis Laboratories for experimental research in high energy physics.

Professor Lederman, a popular international figure in high energy physics, led the team that discovered the Upsilon particle in 1977, which indicated the existence of one, and possibly two new quarks. In the past he participated in the first observation of the non-conservation of parity in muon decay, and in the demonstration of the existence of two different kinds of neutrinos.

Professor Lederman succeeds Dr Robert Wilson who has been the director of Fermilab since it was founded by the US Atomic Energy Commission in 1967, but he resigned in July this year after a dispute over funds for Fermilab's Energy Doubler project known as "Tevatron", which allow external target experiments of up to $1,000 \mathrm{GeV}$. 